\title{
Engineering Undergraduates Concurrently Seeking K-12 STEM Teacher Li- censure: Fuels the Soul or Too Many Barriers?
}

\author{
Dr. Malinda S. Zarske, University of Colorado, Boulder
}

Malinda Zarske is a faculty member with the Engineering Plus program at the University of Colorado Boulder. A former high school and middle school science and math teacher, she has advanced degrees in teaching secondary science from the Johns Hopkins University and in civil engineering from CU-Boulder. Dr. Zarske teaches undergraduate product design courses through Engineering Plus as well as STEM education courses for pre-service teachers through the CU Teach Engineering program. Additionally, she mentors graduate and undergraduate engineering Fellows who teach in local K-12 classrooms through the Integrated Teaching and Learning Program's TEAMS initiative, is on the development team for the TeachEngineering digital library, and is faculty advisor for CU-Boulder's Society of Women Engineers (SWE). Her primary research interests include the impacts of project-based service-learning on student identity, pathways and retention to and through K-12 and undergraduate engineering, teacher education and curriculum development.

\section{Dr. Janet Y. Tsai, University of Colorado, Boulder}

Janet Y. Tsai is a researcher and instructor in the Engineering Plus program at the University of Colorado Boulder. Her research focuses on ways to encourage more students, especially women and those from nontraditional demographic groups, to pursue interests in the eld of engineering. Janet assists in recruitment and retention efforts locally, nationally, and internationally, hoping to broaden the image of engineering, science, and technology to include new forms of communication and problem solving for emerging grand challenges. A second vein of Janet's research seeks to identify the social and cultural impacts of technological choices made by engineers in the process of designing and creating new devices and systems. Her work considers the intentional and unintentional consequences of durable structures, products, architectures, and standards in engineering education, to pinpoint areas for transformative change.

\section{Dr. Jacquelyn F. Sullivan, University of Colorado, Boulder}

Jacquelyn Sullivan is founding co-director of the Engineering Plus degree program in the University of Colorado Boulder's College of Engineering and Applied Science. She spearheaded design and launch of the CU Teach Engineering Program to provide a pathway through a design-based engineering degree for engineering students to simultaneously seek math or science secondary teacher licensure. Sullivan led the founding of the Precollege division of ASEE in 2004; was awarded NAE's 2008 Gordon Prize for Innovation in Engineering and Technology Education, and was conferred as an ASEE Fellow in 2011. She has served on multiple NAE committees, and on the NSF ENG division's Advisory Committee.

\section{Dr. Marissa H. Forbes, University of Colorado, Boulder}

Marissa H. Forbes is a research associate in the College of Engineering and Applied Science at the University of Colorado Boulder and lead editor of the TeachEngineering digital library. She previously taught middle school science and engineering and wrote K-12 STEM curricula while an NSF GK-12 graduate engineering fellow at CU. With a master's degree in civil engineering she went on to teach advanced placement and algebra-based physics for the Denver School of Science and Technology, where she also created and taught a year-long, design-based engineering course for seniors. Forbes earned her PhD in civil engineering, with an engineering education research focus.

\section{Denise W. Carlson, University of Colorado, Boulder}

Carlson is involved with a broad range of program implementation initiatives through the Integrated Teaching and Learning Program at the University of Colorado Boulder's College of Engineering and Applied Science, including the TeachEngineering Digital Library. She holds a BA in economics from the University of Michigan Ann Arbor. She serves as a contributing author and editor of many publications, proposals, presentations and curricula. 


\section{Engineering Undergraduates Concurrently Seeking K-12 STEM Teacher Licensure: Fuels the Soul or Too Many Barriers?}

\section{Introduction}

The benefits of infusing K-12 education with engineering - specifically engineering design and design habits of mind - is well established; engineering design is a powerful vehicle for science and math education [1]. Engineering education research suggests that students who are exposed to engineering topics during their elementary and secondary years are more motivated to enroll and succeed in advanced science, technology, engineering and mathematics (STEM) courses in middle and high school, as well as eventually pursue engineering and other STEM careers [1, 2]. Moreover, students who enter undergraduate engineering programs with prior teaching and mentoring experience often search for avenues to continue such engagement, including paid and volunteer positions in formal and informal K-12 educational settings. Countless K-12 engineering education programs at postsecondary institutions have emerged from the collective desire of industry partners, local engineering faculty, individual practicing engineers, as well as engineering undergraduate students to stay connected to the K-12 community.

According to data from the National Science Foundation (NSF), nearly $30 \%$ of engineering undergraduates work in jobs in non-engineering fields immediately following graduation [3, 4], and preliminary data from the University of Colorado Boulder suggest that post-graduation K-12 teaching pursuits hold appeal for undergraduate engineering students. In 2012, the College of Engineering and Applied Science surveyed its undergraduate engineering student body about a broad spectrum of potential degree and career choices, which yielded a surprising result: $25 \%$ of respondents across the college "agreed" or "strongly agreed" that they "would be interested in earning grades 7-12 science or math teaching licenses while [they] earn[ed] [their] engineering degrees" [5]. The following year, the college launched the Engineering Plus program, a nationally unique design-focused and flexible engineering program $[5,6]$ that requires students to complete an engineering emphasis (aerospace, mechanical, architectural, civil, electrical or environmental) combined with a purposeful sequence of electives (dubbed a concentration) from 20+ options, such as the $C U$ Teach Engineering option for STEM teacher licensure preparation.

The $C U$ Teach Engineering program facilitates students in pursuing both engineering and K-12 teaching passions - educating and preparing a workforce of secondary teachers capable of highlevel teaching in multiple STEM subjects. Engineering Plus students who complete the $C U$ Teach Engineering concentration graduate with a design-focused engineering degree (designed for ABET-accreditation, which the program is currently seeking) coupled with either science (biology, chemistry or physics) or mathematics secondary teacher licensure preparation. The program infuses the design-focused engineering curriculum with education pedagogy courses, extensive science or math content, and a student teaching semester, all in a nine-semester BS degree program, and is a nationally unique early pilot for engaging engineers in K-12 STEM education at scale. Program graduates are prepared to practice engineering and/or to teach (engineering-infused) secondary math or science and engineering design courses.

Three years into the program, Engineering Plus has grown in size and stature, with 134 pioneering students currently enrolled. The $C U$ Teach Engineering concentration is popular among the Engineering Plus students, tied (with business) for the second most-popular 
concentration integral to their design-focused, choice-rich engineering degree (engineering management is the most popular). And yet, the number of students enrolled in the $C U$ Teach Engineering concentration does not nearly reflect the scale of interest initially expressed by the undergraduate engineering student body on a 2012 survey: while one-quarter of the almost 1,000 respondents indicated an interest in K-12 teaching on the survey, just 14 students are currently pursuing the $C U$ Teach Engineering concentration. What is keeping those who indicated a hypothetical interest in K-12 teaching from enrolling in it and pursuing secondary STEM teacher licensure as part of their engineering degrees? This paper seeks to begin probing this complex question by taking a historical perspective, integrating data from the initial launch of the program with recently collected qualitative and quantitative data to analyze the observed discrepancy in self-reported teaching interest versus actual enrollment.

\section{Research Questions}

This research generally explores the interests and attitudes of undergraduate engineering students pursuing STEM teaching licenses concurrently with engineering bachelor's degrees. This paper addresses two primary research questions:

1. How are engineering students who pursue STEM teaching licensure different or similar to engineering students who participate in teacher education courses but decide not to pursue the full licensure pathway?

2. How can the Engineering Plus program faculty and administration better support engineering students who wish to work in K-12 STEM communities achieve teacher licensure?

\section{Methods}

As an early voyager into this type of program for engineering students, we have peered into many perspectives of our data with various samples of students. Our methods have alternated between qualitative data collection and quantitative survey data as the Engineering Plus (E+) program directors, together with the $C U$ Teach Engineering $(\mathrm{E}+\mathrm{T})$ program faculty, identified areas of interest to probe with students committed to the STEM teaching licensure pathway and those just "dipping their toes" into K-12 teaching.

Data collection began in 2014 and continues to adapt to inform program communications to students, to refine internal processes and policies, and for research purposes to better understand the myriad influences on student intentions to pursue E+ and E+T degrees. Surveys, focus groups, and interviews for students were conducted under the University of Colorado Boulder's Institutional Review Board (IRB) approval, reviewed annually by external and internal evaluators. Student names have been changed to conceal their identities.

At various stages in the program launch and pilot, engineering education researchers collaborated with researchers from the university's School of Education to facilitate focus groups, administer surveys, analyze data, and reflect on the many differences between the two disciplines integrated in the $\mathrm{E}+\mathrm{T}$ degree pathway.

In this section, we present first a broad overview to illustrate the full scope and timing of both qualitative and quantitative data collection over the last two years (Table 1), and then describe the analysis processes that led to the emergent findings presented in the next section. 
Table 1. Summary of mixed-methods data collection.

\begin{tabular}{|c|c|c|c|}
\hline $\begin{array}{l}\text { Semester } \\
\text { Method }\end{array}$ & $\begin{array}{c}\text { Target } \\
\text { Population }\end{array}$ & Focus / Intention & $\begin{array}{c}\text { Number of } \\
\text { participants }\end{array}$ \\
\hline $\begin{array}{l}\text { November } 2014 \\
\text { Quantitative survey }\end{array}$ & Enrolled E+ students & $\begin{array}{l}\text {-To gauge interest and awareness } \\
\text { across available engineering degree } \\
\text { pathways, including teaching }(\mathrm{E}+\mathrm{T})\end{array}$ & 22 \\
\hline $\begin{array}{l}\text { Spring } 2015 \\
\text { Qualitative focus } \\
\text { groups }\end{array}$ & $\begin{array}{l}\text { E+ students, recent } \\
\text { completers of the } \\
\text { first step of the } \\
\text { teaching licensure } \\
\text { pathway }\end{array}$ & $\begin{array}{l}\text { - To explore engineering students' } \\
\text { experiences in education courses } \\
\text { - To peer into engineering and } \\
\text { educational identity development, } \\
\text { and motivations for pursuing E+T vs. } \\
\text { E+ degrees with non-teaching } \\
\text { concentrations }\end{array}$ & $\begin{array}{l}3 \text { focus groups } \\
\text { comprised of } 8 \\
\text { student } \\
\text { participants }\end{array}$ \\
\hline $\begin{array}{l}\text { October } 2015 \\
\text { Survey }\end{array}$ & $\begin{array}{l}\text { Enrolled E+T } \\
\text { students }\end{array}$ & $\begin{array}{l}\text { - To assess perceived effectiveness of } \\
\text { the E+T pathway } \\
\text { - To assess perceived differences } \\
\text { between engineering and education } \\
\text { students across campus }\end{array}$ & 10 \\
\hline $\begin{array}{l}\text { Spring } 2016 \\
\text { Qualitative } 1 \mathrm{x} 1 \\
\text { Interviews }\end{array}$ & $\begin{array}{l}\text { Students who } \\
\text { completed two } \\
\text { Education courses } \\
\text { along the E+T } \\
\text { pathway }\end{array}$ & $\begin{array}{l}\text { - To examine individual attitudes and } \\
\text { desires for pursuing E+T vs. leaving } \\
\text { the licensure part of the program }\end{array}$ & $\begin{array}{c}5 \text { student } \\
\text { participants: } 4 \\
\text { enrolled in E+T } \\
\text { pathway, and } 1 \\
\text { E+T "leaver" }\end{array}$ \\
\hline $\begin{array}{l}\text { Fall } 2016 \\
\text { Survey }\end{array}$ & $\begin{array}{l}\text { Newcomers to the } \\
\text { E+ degree program }\end{array}$ & $\begin{array}{l}\text { - To gauge interest in teacher licensure } \\
\text { across available concentrations and } \\
\text { disciplinary emphases } \\
\text { - To assess perceived effectiveness of } \\
\text { communication from the program to } \\
\text { students }\end{array}$ & 31 \\
\hline $\begin{array}{l}\text { Fall } 2016 \\
\text { Qualitative } 1 \times 1 \\
\text { Interviews }\end{array}$ & $\begin{array}{l}\text { Transfer E+ students } \\
\text { and recent } \\
\text { completers of first } \\
\text { step teaching license } \\
\text { pathway, intending } \\
\text { to continue }\end{array}$ & $\begin{array}{l}\text { - To learn from unique transfer student } \\
\text { perspective on differences between } \\
\text { engineering and education sides of } \\
\text { campus } \\
\text { - To investigate if/how perceptions of } \\
\text { the E+T program have changed since } \\
\text { the spring } 2015 \text { focus groups }\end{array}$ & $\begin{array}{c}2 \text { student } \\
\text { participants }\end{array}$ \\
\hline
\end{tabular}

\section{Participants and Study Design}

In our exploratory mixed-methods research design [7], qualitative and quantitative stages of data collection proceeded sequentially, with each dataset informing the design of the subsequent 
survey or interview protocol. The 2014 survey of enrolled students into the E+T pathway revealed a much smaller number pursuing this interest than anticipated. This discrepancy prompted our qualitative investigation into the motivations, attitudes, and identity development of the enrolled E+T students. The 2015 focus group protocol was designed with these needs in mind; the guiding questions probed perceived differences in educator versus engineer status, identity, and stereotypes, while seeking to understand difficulties or obstacles engineering students faced while on the E+T pathway. See the Appendix for the full protocol.

Based on the findings and emergent themes from the 2015 focus groups, the need to quantitatively assess the perceived effectiveness of the E+T program and the perceived differences between engineering and education students necessitated a survey of the students currently pursuing the E+T pathway. That survey's quantitative data results further prompted us to conduct a qualitative interview study to more deeply understand the E+T students' individual experiences. From the overall pool of E+T students who had completed at least two courses along the teaching licensure pathway, five interview participants were selected for in-depth oneon-one interviews. These interviews provided an opportunity for the enrolled students to tell their own stories, explain in their words how and why they made their particular curricular choices, how they felt about their education and engineering course experiences, how they saw E+T fitting in with their eventual careers, and more. While the interviews do not represent matched cohorts, a purposive sampling approach was adopted to recruit these interview participants, as we sought to hear the stories of a few students who remained in the E+T pathway as well as several who chose to leave [8]. Only one "leaver" responded to our requests for interview, resulting in four of the five interview participants being continuing E+T enrollees. See the Appendix for an example interview protocol for this stage of qualitative data collection.

In fall 2016, as the E+ degree program continued to gain momentum and grow in size, program leaders and faculty wanted to understand the newcomers' perspectives about the design-rich E+ program since it had evolved significantly since its 2013 inception. This survey had two main foci: to gauge student interest across the $\sim 20$ available E+ concentrations and six disciplinary emphases (which could result in 120 different degree combinations) and to assess the perceived effectiveness of communication from the E+ program to students. This way, program leaders could continue to understand the context for students in E+ who were choosing E+T instead of choosing among the $\sim 18$ non-teaching concentrations. Building on the findings and themes from the prior qualitative focus groups and one-on-one interviews, two additional interview participants were selected from the newcomer survey respondents who indicated an interest in the E+T pathway and had just completed their first E+T courses. The intent of the fall 2016 interviews was to further explore if and how perceptions of the E+T program had changed since the 2015 focus groups and surveys, and to add additional individual stories to the corpus of qualitative interview data. Thus, the interview protocol for the fall 2016 interviews was similar to the spring 2016 interview protocol (see the Appendix).

\section{Qualitative Data Analysis Methods}

A previous conference publication detailed a segment of the data analysis process, including third-party coding validation of the spring 2015 quantitative survey results and qualitative focus group transcripts based on a set of descriptive codes determined by the authors $[9,10]$. In this paper, we delve more deeply into the descriptive code of identity threats and reconciling as well as a trajectory-based analysis of the individual interviewees. This is a new and distinct approach 
to understanding and categorizing these students, not previously reported or analyzed in this way in prior publications. As this specific coded data and individual trajectory analysis pertains to students navigating challenges (or threats) to their identities as engineers and educators, it is particularly rich in illustrating the unique obstacles and questions that students pursuing the $\mathrm{E}+\mathrm{T}$ pathway encounter from peers, families, and themselves.

For this paper, analysis of all one-on-one interviews began with creation of contact summary forms as a simple method of explaining the context and main themes emerging from each interviewee, individually [9]. This enabled case-by-case understanding and gradual categorization of cases into one of three emergent trajectory categories along the E+T pathway: 1) students who wanted to attend the University of Colorado Boulder and enroll in the E+T program from the start of their undergraduate experiences, 2) students who were enrolled in traditional engineering majors before an industry experience (either engineering or education) convinced them to switch into the E+T (or just teaching) pathway, and 3) engineering students who were enrolled in $\mathrm{E}+\mathrm{T}$ but then left the $\mathrm{E}+$ program for traditional engineering majors.

Combining analysis of individual trajectories with the focus group narratives resulted in recommendations for program improvement, targeted communications to students to alleviate misconceptions about teaching careers, and a holistically better sense of the tradeoffs engineering students face in pursuing E+T degrees, as explained in the Findings section.

\section{Quantitative Data Analysis Methods}

Administered via Qualtrics ${ }^{\circledR}$ Research Suite online survey software, the fall 2014, fall 2015, and fall 2016 surveys consisted of items answered via multiple choice (e.g., yes/no) and text entry. The full survey items for each are provided in the Appendix. In addition, the fall 2014 and 2016 surveys include questions around teaching that are focused using an if/then skip logic, dependent on participants' responses. For example, if a participant responded that $\mathrm{s} / \mathrm{he}$ was interested in teaching ("yes"), then the facilitator moved on to a question that asked to what extent certain factors influenced his/her decision to pursue a teaching license. All respondents self-select to complete the survey. The specific results for each survey are addressed in the findings below.

\section{Findings}

\section{Quantitative Findings-Fall 2014 Survey Findings}

As program evaluation of the new Engineering Plus degree developed, the fall 2014 survey of Engineering Plus students was implemented to query student perceptions of the major, students' interests (including secondary STEM teaching), and suggestions for program improvement. Twenty students (44\% of program enrollment) completed the survey and offered insights into the attraction of a teaching license within a design-focused engineering degree. Of the responses, $50 \%(n=10)$ students were interested in teaching. Of those interested, only $50 \%(n=5)$ were enrolled and taking education courses. The overall interest in teaching was higher for this small sample than the original college-wide survey, but still only $25 \%$ of the sample were actively pursuing the STEM licensure path.

Of the five students who were interested but not currently taking education courses, only two indicated that they seriously considered earning teaching licenses. We probed deeper into 
possible factors that influenced their decisions to pursue STEM teaching licenses, asking them to rank possible influencers as "not at all important," "somewhat unimportant," "neither important nor unimportant," "somewhat important," or "extremely important." (See Table 2, with the factor ranking from 1-highest influence to 9-lowest influence.) All students who were interested in teaching licenses indicated that to "make a difference in children's lives" was the most influential factor in their decisions to try E+T, while students who were interested in teaching but not considering a teaching license indicated that "interest in teaching" and "passion for the subject matter" also influenced their ultimate decisions (followed by low pay).

For students who were already exploring the E+T pathway by taking education courses $(n=5)$, to "make a difference in children's lives" was coupled with "passion for the subject matter," "job security" and "teaching runs in the family," as their top four factors that played an influencing role in their decisions to pursue teaching licenses. 
Table 2. Results from fall 2014 survey; rank order of factors influencing E+ students' decisions to pursue teaching licenses, with a rank of 1 (darkest cell color) indicating the highest influence on decision.

\begin{tabular}{|c|c|c|c|c|c|c|c|c|c|c|c|}
\hline & 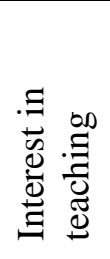 & 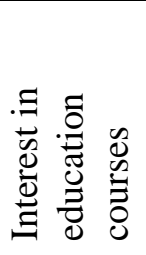 & 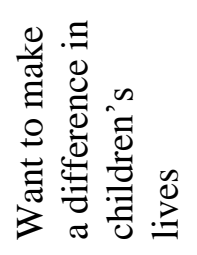 & 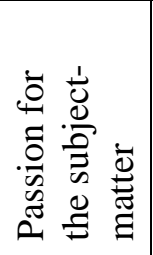 & 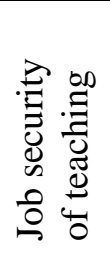 & 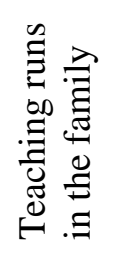 & 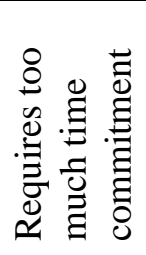 & 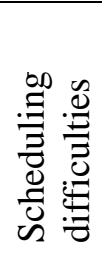 & 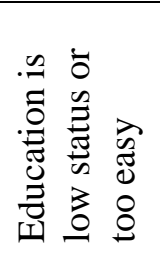 & 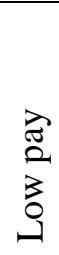 & 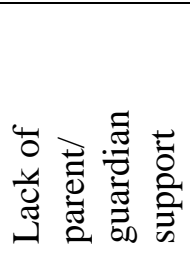 \\
\hline $\begin{array}{l}\text { Students who are interested } \\
\text { in teaching but not taking } \\
\text { any education courses and } \\
\text { not interested in teaching } \\
\text { licensure }(n=3)\end{array}$ & 1 & 5 & 1 & 2 & 7 & 8 & 4 & 4 & 6 & 3 & 5 \\
\hline $\begin{array}{l}\text { Students who are interested } \\
\text { in teaching but not taking } \\
\text { any courses and are } \\
\text { interested in teaching } \\
\text { licensure }(n=2)\end{array}$ & 2 & 3 & 1 & 2 & 2 & 3 & 2 & 4 & 6 & 2 & 5 \\
\hline $\begin{array}{l}\text { Students who are interested } \\
\text { in teaching and are already } \\
\text { taking education courses } \\
(\mathrm{n}=5)\end{array}$ & 1 & 5 & 1 & 2 & 3 & 4 & 7 & 6 & 9 & 7 & 8 \\
\hline
\end{tabular}




\section{Qualitative Findings-Spring 2015 Focus Groups}

From the results of the fall 2014 survey, a need to further explore the thinking behind engineering students' choices to pursue E+T or even consider the teaching pathway prompted the research team to conduct focus groups with engineering students currently enrolled in an E+T course. Three excerpts from these focus groups are included below; they powerfully illustrate the issues undergraduate engineering students face in explaining their choices to pursue the E+T program to their peers and families:

\section{Excerpt \#1, Focus Group 1, Betsy:}

My engineer friends are like, "So what's your area of emphasis if you're in applied math now?" And I say, "Education," they're like, "Is that a complete joke?"

They really discredit it. They're like, "Seriously, you do all this work in applied math to be a teacher? You're gonna teach seventh grade math when you're taking Fourier [Analysis] and these really hard classes that seventh graders would never need to know."

So I think they think it would just be an overqualified thing. They're like why would you like-I think they just kind of see it as like I'm a slacker sort of.

This excerpt reveals Betsy's description of her peers' reactions to her pursuing concurrent applied math and education degrees. After being questioned as a "complete joke," Betsy goes on to explain how her peers "discredit" her chosen STEM teaching trajectory because they apparently do not understand why a seventh-grade math teacher would benefit from understanding complicated mathematical topics such as Fourier analysis. Betsy reflects that she is seen as a "slacker" by her peers, as they are apparently discrediting the amount of work and coordination required to pursue a teaching and engineering degree simultaneously.

\section{Excerpt \#2, Focus group 2, Jennifer, Anton, Carl}

Jennifer: I have been laughed at once. I was saying I'd love to just teach high school science or something. They're like, well why are you taking this class? Like, why are you taking o[organic] chem? I'm like, well because I wanna be an engineer, too. I don't know. They're like, you could just take normal chemistry. Like, you don't need to take-like, why are you in an engineering program that's so much more vigorous. But that was it.

Anton: 'Cause it's more vigorous.

Jennifer: Yeah, exact-I'm like, well I know it. It's fun.

Moderator: And there was, like, no pushback after that or was-

Jennifer: No. No, they were just kinda laughing. It wasn't, like, bullying. It was just, like-it was just, like, what are you doing? Like, why are you making it so much harder on yourself?

This passage reiterates the apparent ignorance on the part of other undergraduate engineering students that secondary school teachers might benefit from the rigor of notoriously difficult classes such as organic chemistry. The perception that engineering is much more "vigorous" than 
other degree programs on campus, including education or the liberal arts, is paramount to how these engineering students characterize their world; students in the E+T program must continually face the question from uninformed peers about the logic of "making it so much harder" on oneself.

\section{Excerpt \#3, Focus group 2, Jennifer, Anton, Carl}

Carl: I've had that exact same experience. When I tell people I wanna be a math teacher, they're like, "Wait, but you're an engineering major." I'm like, "So [what]?"

So, like [Jennifer] said, there's definitely tension, even talking to friends and family and just-obviously they know I love teaching and I love engineering, but it's like-I don't know. I feel like there's definitely a view of - that's kind of true that, teaching is a lot harder to make your way in [life] versus engineering. I mean just even looking at starting salaries, you have 25-ish, maybe, if you're a teacher and you have closer to the 100s if you're engineering. So it's hard. Especially if you wanna stay in places like Boulder where it's not exactly cheap to live. So I think there's a tension that way. Not necessarily like within myself, but kinda with friends and family and stuff and the way they view my degree. And to be fair, they're all fully supportive of everything but, in that manner, I think there is tension.

In this excerpt, Carl builds on the conversation with Jennifer and Anton, bringing in the discrepancy in starting salaries of entry-level teachers versus entry-level engineers to additionally quantify the tension in how others perceive his degree program choices. While the salary amounts Carl cites are exaggeratedly low for entry-level teachers and high for budding engineers, they show how some engineering students generally envision their immediate postgraduation earning potential, and explain why financially motivated students are inclined to belittle or be skeptical of the choice to be a math or science teacher instead of an engineer. Carl is quick to point out that his network is "fully supportive of everything," yet this support does not eliminate the "tension" that he feels from his friends and family about pursuing his passions in both teaching and engineering.

From the spring 2015 focus groups, it is clear that the E+T pathway is neither smooth nor uncontested - students pursuing concurrent engineering and teaching degrees are constantly navigating how others interpret their choices to take rigorous engineering courses and "make it harder" on themselves even if they are "just" going to be teachers. Even for students who "love" both engineering and teaching, "tensions" between the two disciplines are palpable because of the perceived differences in course difficulty, earning potentials, and overall career trajectories.

\section{Fall 2015 Survey Findings}

By fall 2015, 15 students were engaged in the E+T pathway. Following up on the themes that emerged in the focus group discussions, this survey specifically explored how students navigate engineering majors with teaching license pathways (and reported in a previous conference paper) [9]. Sixty-six percent $(n=10)$ of the 15 E+T students completed the survey-30\% women $(n=3)$ and $70 \%$ men $(n=7)$ - and represented a spectrum of academic standing: two seniors, three juniors, four sophomores and one first-year student. While survey results indicated that engineering students found their developing education pedagogy valuable across disciplines and 
reported the use of teaching strategies when working with multidisciplinary engineering design teams, they also found the E+T pathway difficult to navigate in part due to the perception of differences between engineering and education. Of the respondents, $80 \%(n=8)$ reported perceived differences between the engineering and education fields in general, while $60 \%(n=6)$ perceived character differences between engineering and education majors. Adding survey data to the qualitative focus group findings, we found that the persisting E+T students not only must navigate the degree pathway, but also the physically and culturally different environments of engineering and education courses on campus. We had not anticipated these difficulties.

\section{Fall 2016 Newcomers Survey}

In fall 2016, we surveyed the newly joined E+ majors about the program, including their knowledge of, and interest in, the teaching licensure pathway. Of the 29 respondents, only eight (28\%) had ever considered teaching in a K-12 setting (see Table 3, in green).

Table 3. Few newcomer students had considered K-12 teaching.

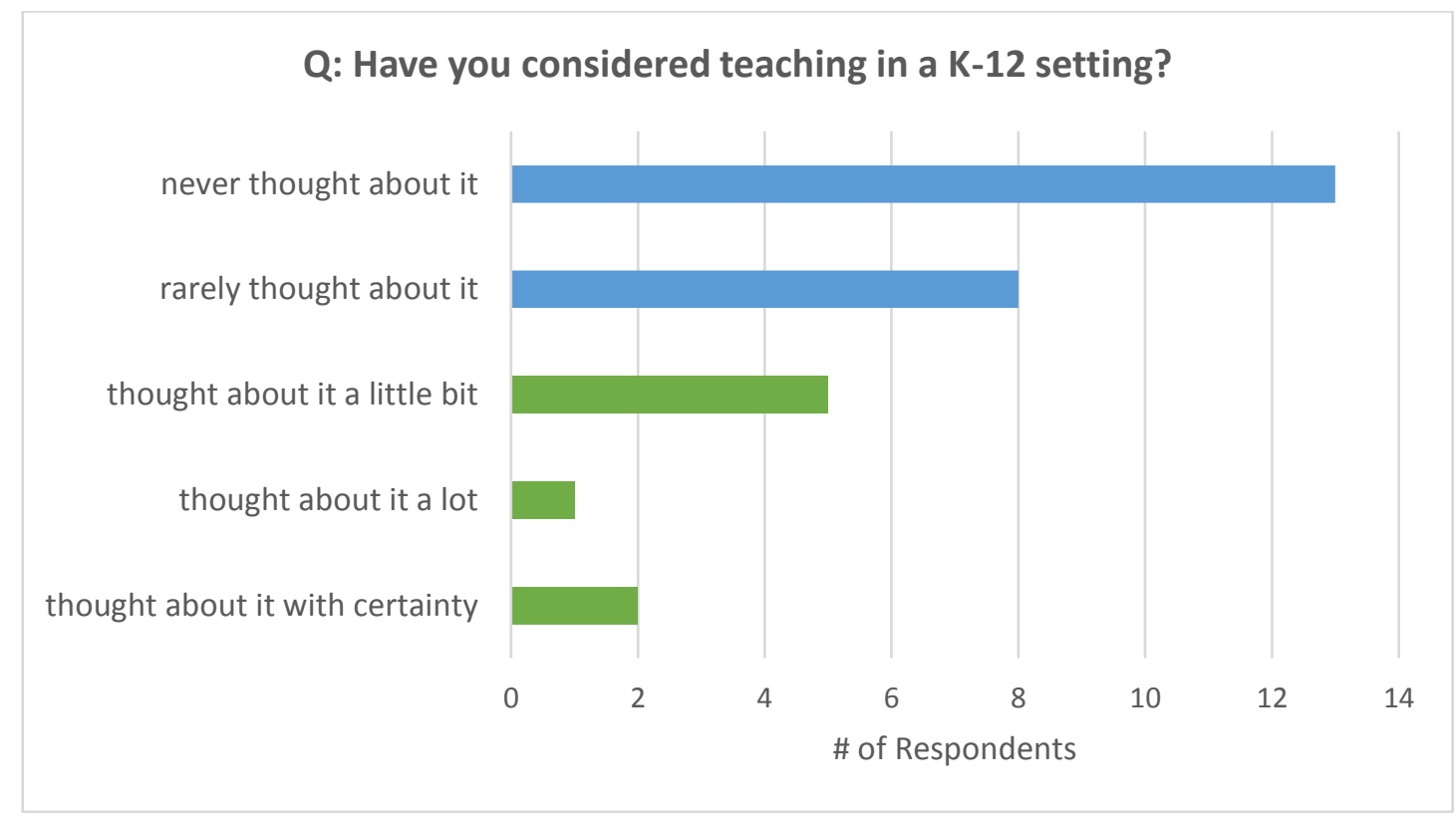

The survey also included an open-ended probe into the reasoning around their answers, with several responses provided below. Students who were not interested in an E+T pathway answered:

- (I) want to be using my skills to innovate rather than teach.

- I would be extremely dissatisfied with the pay and my own abilities to encourage and motivate my students to succeed.

- It could be fun, but the pay is not very good and I don't know if I would enjoy it.

- Although not averse to working with children or teaching in general, [I have] absolutely no personal interest in participating in a broader school system.

- It does not seem like something I would enjoy. 
In contrast, responses from engineering students who had considered a teaching pathway included:

- I enjoy working with kids and I enjoy teaching.

- I am going for my teacher licensure in mathematics.

- I was a math tutor for four years in high school and it felt good when students (from seventh to my grade) would tell me I taught better than their teachers did and broke down concepts. I normally taught lecture style. I just sorta enjoyed "having the stage," but also improving their minds for future problems.

This survey also asked what information would be helpful to E+ students to aid them in considering the E+T math or science licensure-focused concentrations. While several respondents said they were simply not interested, a few students offered, "how it works and how it is different from traditional teaching paths," "perhaps by demonstrating that the pay is good and leads to a satisfactory career," "international teaching opportunities or programs," and "the only problem I see with wanting to go down an E+T pathway would be the five-year program School is very expensive and I don't know if I am up for another year." [The E+T program is, in fact, a nine-semester endeavor].

\section{Spring and Fall 2016 Qualitative Interview Findings}

Analysis of individual interviews complements the findings from the 2015 focus groups, the fall 2015 survey and fall 2016 newcomers survey to reveal how student trajectories into the E+ program may affect how they navigate the tensions and identity conflicts described in the prior quantitative and qualitative data.

Table 4 groups the seven interviewees into three emergent categories: 1) students who wanted to attend our institution and enroll in the E+T program from the start of their undergraduate careers, 2) students who were enrolled in traditional engineering majors before an industry experience (either engineering or education) convinced them to switch into the $\mathrm{E}+\mathrm{T}$ (or just teaching) pathway, and 3) students who were enrolled in E+T but then left the program for a traditional engineering major. After Table 4, short narrative statements for each of the interviewees provide additional detail on how they tell the stories of their E+T involvement. 
Table 4. Summaries of spring and fall 2016 interview participant trajectories.

\begin{tabular}{|l|l|c|l|}
\hline \multicolumn{1}{|c|}{$\begin{array}{c}\text { Trajectory to E+T } \\
\text { Degree Pathway }\end{array}$} & Student & $\begin{array}{c}\text { Status in E+T } \\
\text { Program }\end{array}$ & \multicolumn{1}{c|}{$\begin{array}{c}\text { Plans Immediately Following } \\
\text { Graduation }\end{array}$} \\
\hline \multirow{2}{*}{$\begin{array}{l}\text { Wanted to attend the } \\
\text { University of Colorado } \\
\text { Boulder and E+T } \\
\text { program from outset }\end{array}$} & Winston & $\begin{array}{c}\text { Enrolled, transfer } \\
\text { sophomore }\end{array}$ & $\begin{array}{l}\text { Work in engineering industry for 5+ } \\
\text { years, then "come back to teaching after" }\end{array}$ \\
\cline { 2 - 4 } & Luis & $\begin{array}{c}\text { Enrolled, transfer } \\
\text { sophomore } \\
\text { industry }\end{array}$ & $\begin{array}{l}\text { Work as an engineer in developing } \\
\text { communities for 20+ years, then come } \\
\text { back and be a teacher }\end{array}$ \\
\hline $\begin{array}{l}\text { Experience in industry } \\
\text { (teaching or } \\
\text { engineering) } \rightarrow \text { changed } \\
\text { majors / career } \\
\text { directions to E+T }\end{array}$ & Kat & Enrolled, junior & Teach in middle school \\
\cline { 2 - 5 } & Scott & $\begin{array}{l}\text { Enrolled in T, } \\
\text { master's student }\end{array}$ & Teach in high school math \\
\hline Left E+T & Nora & Left E+T, junior & Work in engineering industry \\
\hline
\end{tabular}

Wanted to attend University \& E+T program from outset

Seth met a University of Colorado Boulder administrator early on: "When I was first enrolling here and met with him, he said that it would be great for me to start in this (E+) program anyway, even though I wasn't sold on engineering at the time, because he said if you get into the engineering school and decide you don't like it, it would be really easy to get out of it and just go solely into teaching. So he's like it's harder to go from teaching to both than it is to go from both to one. So it wasn't immediately in my mind, but then when everything kind of fell together the way it did so easily, then it was kind of a no brainer. It wouldn't make sense not to at least try it type of thing. And so that's kind of how and why I did it."

Winston is a transfer engineering student in his first semester at the university: "When I was accepted into the E+ program, I found out that teaching was offered and I got really excited about that, because that was what I was split between, either teaching or engineering. And my whole family's teachers, and so going into engineering is kind of against the grain as far as that goes, and so finding an opportunity to do both-'cause I'm really passionate about teaching, and I'm really passionate about engineering..."

Luis: "Deep inside I've always had a passion of teaching. Ever since I was in middle school I've always wanted to teach math and influence kids from my neighborhood, that's been rough, help them get through college and stuff, and show them some engineering ways. And people have always told me to go into engineering, but I never really knew what it was, basically, until I got here."

Experience in industry (teaching or engineering) $\rightarrow$ changed majors / career directions to $E+T$ Kat worked as a camp counselor at a science camp in the summer after her sophomore year and 
realized she did not want to be a chemical engineer after all. She googled "education and University of Colorado" and E+T popped up. She wanted to remain in engineering because she "was so far into it already that I might as well just finish it." E+T offered her a pathway to continue forward without "giving up," though she wishes more of her chemical engineering coursework transferred in to satisfy E+ degree requirements. She adds, "My goal is to always teach and never do engineering. But it [engineering] is just a nice fallback."

Doug was a civil engineering major who interned at a local transportation engineering government office over the summer, then realized he didn't want to do transportation engineering after all. He tried being a physics major, but then switched to E+ in part because of interest in education and the E+T pathway. As he was looking for another course to increase his credit hour load, he "stumbled upon the introductory teaching course" and said "it was a good find."

Scott graduated with a BS in civil engineering, worked for one year, then decided engineering was not for him and teaching would be a better fit: "I really, truly believe that teaching will be something that will fuel my soul in a different way than engineering could."

Growing pains and poor cross-campus coordination between engineering and education Nora joined the E+T program as soon as it was available, but she later switched out of the program due to miscommunications with advisors between the School of Education and E+: "Between the engineering school and the education school, the advisors were not talking very well, and I was stuck in the middle. It is expected at the beginning of the program to have problems like that, but it was going on for a really long time, and I got really frustrated. I decided it was time to leave because - especially the advisors at the education school, they were not helping me out at all."

\section{Findings from Qualitative Data}

Integrating across the qualitative focus group data and interview data, we see that students enrolled in the dual pathway E+T are distinctive in many ways. They face tensions and questioning judgments from their peers and friends about the choice to challenge themselves in rigorous engineering coursework if they are "just" going to be teachers, which also subtly demeans their teaching aspirations. While ostensibly supportive, some family members and friends may also be concerned about the financial divide between entry-level teaching and engineering salaries, and voice concerns about how E+T degrees will provide for comfortable futures and long-term acceptable standards of living. Yet in investigating individual student perspectives through interviews, we find that these E+T students are also uniquely and intrinsically motivated to face these tensions and challenges. Several interviewees and focus group participants mentioned being deeply passionate about teaching or loving both teaching and engineering, while others discussed in vivid detail how specific experiences in the workplace convinced them to switch majors or career paths and pursue simultaneous teaching licensure. It may be that these intrinsic convictions or personal experiences help students stay on the E+T pathway in spite of assumptions or judgments by others about the higher "societal status" of engineering versus teaching [10].

Interestingly, five of the seven E+T students interviewed planned to work in engineering industry 
or attend engineering graduate school immediately following graduation from the E+T program, with teaching as something they will "come back to" after several years as practicing engineers. Another thread emerging from the qualitative data suggests that engineering students are advised about the opportunity cost in pursuing teaching initially over engineering; in some cases (like Seth, above), authority figures have explicitly told students that it is "easy" to switch from E+T to "just" teaching, while it would be more difficult to move from teaching into engineering.

Throughout the process of qualitative data collection, in asking the E+T students to envision their future plans post-graduation, we ask them to forecast their lives at least two to three years away from the present. Looking forward is always uncertain, and pragmatically, these students may lean towards the side of what enables them to keep their options open. Coupled with the prevalent attitude that engineering is more rigorous and difficult than education, at least on the undergraduate level, it follows that students anticipate to start with what seems "harder" to get into (an engineering career) before "coming back" to the "easier" or more accessible teaching pathway.

Notably, two interviewees plan to teach immediately following graduation. Kat describes her "goal is to always teach and never do engineering," with engineering as "a nice fallback," due to a trajectory-changing experience working as a summer science camp counselor. Similarly, Scott's sentiment that teaching will "fuel [his] soul in a different way than engineering could" is informed by dissatisfaction with his personal experience working in the civil engineering profession. For these two students, switching from engineering to teaching is not a burden in terms of opportunity cost since they no longer aspire to become practicing engineers.

\section{Study Limitations}

The findings of these analyses should be considered within the limitations of the study. First, each author is in some way involved in the E+ degree program; no impartial researchers took part in the study.

Additionally, we note that the overall sample size of participants along the $C U$ Teach Engineering (E+T) pathway is relatively small, and from this group, the number of interviewees is smaller still. The purpose of this research is not to generalize from these interview or focus group excerpts, but rather to learn what we, as program administrators, faculty and developers of curriculum and program culture, can learn from the individual stories of the pioneering students in this novel E+T pathway. In other words, rather than use these students' narratives to generalize to broader populations, we ask what elements of these students' lived experiences might be transferable to others [11]. Not all E+T students will face the exact dilemmas or challenges that these students describe, but some may experience similar judgments or tensions along their pathways towards E+T degrees. In stating our findings, we do not assume these cases are typical; rather, we treat them as individual data points from which we can learn and attune program communications and policies to better accommodate. 


\section{Key Findings and Discussion}

Our first research question asked, "How are engineering students who pursue STEM teaching licensure different or similar to students who participate in teacher education courses but decide not to pursue the full STEM licensure pathway?" From the qualitative data, we have seen that the $C U$ Teach Engineering (E+T) students either chose CU Boulder specifically for the E+T pathway or experienced a critical real-world incident in the engineering profession or within an educational context that motivated them into the E+T pathway. Similar to the other Engineering Plus (E+) students, these students do not necessarily plan to teach in the future - or in the immediate future; the choice to pursue the $\mathrm{E}+\mathrm{T}$ degree is not coupled directly to post-graduation career plans. This finding may indicate that the coupling of design-focused engineering with education could serve as a broad platform from which students launch into myriad career choices - much like the ubiquitous liberal arts degree popular in yesteryear.

Surveying the engineering students who are interested in teaching (either by completing licensure requirements or not) reveals a common desire to make a difference in children's lives coupled with a passion for the engineering subject matter. Those who are considering a teacher license program alongside an undergraduate engineering major also favor the job security of teaching. Obvious considerations of lower ultimate salaries combined with perceived increased time commitment while in college might deter some students from jumping into the dual E+T pathway and taking education courses; this sentiment is expressed in the focus group discussions around disparity in status of engineers and educators among their peers in the engineering college. On the other hand, the E+T students who enroll in courses that lead to STEM teacher licenses are more likely to report that they have family members who are teachers. Perhaps having a family teaching connection helps to overcome uninformed and biased peer comments through personal insight into how teaching careers can meaningfully combine academic interests and fulfillment through service, making a difference in others' lives and communities.

Our second research question asked, "How can the Engineering Plus program faculty and administration better support all engineering students who wish to work in K-12 STEM communities achieve K-12 teacher licensure?" Our findings suggest that we should first resolve the communication difficulties between engineering and education programs that frustrated students like Nora who left E+T and E+ entirely because of feeling "stuck in the middle" of changing policies and uncooperative advising. Additionally, we can explicitly address the underestimate about entry-level teaching salaries by informing students of current data that shows that the earning potential of teachers graduating from $C U$ Teach Engineering exceeds the $\$ 25 \mathrm{~K}$ mentioned in a focus group. Being transparent about the teaching benefits not included in the financial bottom line may help students feel more confident when faced with the judgments by peers and family members who question the logic of simultaneous enrollment in rigorous engineering coursework and education courses. Furthermore, we should more openly acknowledge that some students who choose the E+T pathway plan to pursue engineering careers immediately following graduation; for these students, obtaining $\mathrm{E}+\mathrm{T}$ degrees enables them to keep future options open so they do not feel locked into career paths in either teaching or engineering. 
The program launchers acknowledge that we initially viewed these students' engineering career choices as mild disappointments because we so wanted to immediately contribute graduates to the secondary STEM teacher shortage, and were convinced that our talented engineering students would make strong secondary science or math teachers, uniquely prepared to infuse engineering design and habits of mind throughout schools' STEM curricula. We have become aware of our bias, and now strive to be more open minded about supporting all students' choices, gratified that our $\mathrm{E}+\mathrm{T}$ alums who are practicing engineers uniquely understand the challenges inherent in public urban educational systems such as the one where they student taught.

The $C U$ Teach Engineering program is an early foray into earning simultaneous secondary math and science teacher licensure, through a design-centered engineering degree, for engineering undergraduate students. A pioneer program intending to launch at scale, it weaves engineering design through each year and accommodates extensive STEM teacher preparation via a flexible, customizable engineering degree that simultaneously equips students for the professional engineering workplace. It has not been a trivial launch, given the identity, status and curriculum challenges to navigate and learn from. However, studying the E+T students with various methods and from various perspectives has helped us gain a greater understanding of what is working and what needs improvement.

We recognize that engineering students who choose a teaching pathway are unique. Two distinct differences have emerged to attaining a simultaneous teacher licensure pathway for engineering students, as compared to science or math majors: their technical engineering course loads are quite restrictive and (driven by ABET requirements) amount to at least twice the required credit hours as for science or math majors. Secondly, through the design-focused Engineering Plus curriculum, engineering students attain highly honed problem solving, critical thinking and design skills that are hallmarks of an engineering education.

If the goal is to support engineering students who may wish to work in the K-12 STEM arena to achieve K-12 teacher licensure - bringing engineering more intentionally into the common language of STEM education - then we must address the disparity that exists between schools of engineering and education. Our ongoing research indicates that engineering students who are passionate about teaching and K-12 careers are subject to scrutiny — and even ridicule — of their choices. While their peers (and sometimes family) agree that teaching is an honorable profession in theory, some question the rationale of an engineering student friend or family member pursuing the perceived lower status teaching license. Combined with the perception of differences in rigor between engineering and education coursework (another potential measure of societal status or social capital), the pathway through engineering to STEM teacher licensure remains fraught with social and cultural challenges that programs such as ours must resolve.

\section{Recommendations for Future Work}

We continue to refine the E+ program curricular content, messaging and internal processes based on feedback from $\mathrm{E}+\mathrm{T}$ students as well as our research findings. From the mixed-methods research conducted to date, we have several promising avenues to explore with regards to how we identify and communicate with engineering students potentially interested in teaching. For instance, we may seek out individuals who participated in engineering internships and 
subsequently feel uncertain about continuing along the engineering trajectory, since they may benefit from knowing about the E+T option. This builds on research that suggests that engineering undergraduates may return from summer internships disillusioned with the climate of engineering workplaces or unsure about joining the engineering profession after graduation $[12,13]$. Providing a meaningful alternative to practicing in industry may enable such highperforming students to apply their engineering training and habits of mind within educational environments.

Alternatively, we can recruit engineering students who work as camp counselors, tutors, or educators in some format and let them know about the E+T alternative. Following up on the emergent theme of opportunity cost, we can investigate whether framing E+T as expanding one's options instead of limiting them impacts how students envision their post-graduation futures.

Another option we are investigating to help mitigate the dual identity challenges, the perceived lower status of those on the teaching pathway, and the highly constrained dual curriculum is to move the educational component of the E+T program out of our School of Education for all secondary STEM licensure students (including those in science and math content areas). This would enable the E+T program to streamline the education course content into fewer credit hours, remove curriculum redundancies, put more emphasis on STEM content teaching practice, and create a culture that tightly binds all secondary STEM education majors around the theme of making a difference for youth.

As the CU Teach Engineering program continues to grow and matriculate licensed teachers, we will carefully monitor our graduates' post-degree employment choices and how they tell their stories. Our first E+T graduate just successfully completed her student teaching semester at a highly regarded, public, minority-serving urban STEM high school that is closing the education gap for low income youth in a challenging setting. This pioneering student was well prepared to tackle teaching high school math, exploiting the opportunity to infuse engineering and engineering design into her pre-calculus classes. With more E+T graduates who overcome dual program and dual identity obstacles, challenges, assumptions, and peer judgments, we will have more stories to share, and from which to learn as we help E+T students balance the tensions inherent in navigating this unique combined degree pathway.

Doing something bold and new is not easy. An engineering college venturing into STEM teacher licensure was fraught with risk; as a learning community ourselves, we have learned a lot. Would we do it again? Absolutely. Do we recommend that other engineering colleges engage at scaleway beyond K-12 "outreach" programs - in the tough work of putting the "E" in STEM for youth many years before they contemplate college choices? Absolutely. Only through producing STEM teachers who deeply understand engineering can we do this at scale. Our early results underscore that engineering colleges have an important role to play in STEM teacher production. Capitalizing on the belief that the best should teach and the knowledge that engineering students are among the strongest students on campuses across the nation, we have a societal obligation to engage more meaningfully in the K-12 teaching enterprise upon which we are absolutely dependent for our engineering-bound students. 
Thinking Scale. Creating an accessible pathway through engineering for engineering students to realize their passion of making a difference in children's lives could make engineering much more relevant to the lives of millions of youth. Imagine a world in which 100 engineering colleges each produced 30 STEM teachers annually, each in turn teaching 125 secondary students daily. These 3,000 teachers per cohort would then teach engineering-enriched mainstream STEM topics to 375,000 youth per year! In just four short years, 12,000 engineeringeducated teachers would impact $1.5 \mathrm{M}$ youth, every school day, every year. Now imagine if most of those youth were underserved, from communities where families have little connection to the field of engineering. Imagine our profession achieving real breakthroughs in its long-sought mission to broaden participation in engineering though doing, not hoping others will do for us. Together, this is possible; do we have the will to make the possible probable?

Our goal is to create a STEM licensure through engineering model that can be replicated, or modified for replication, at other engineering colleges, and to share all of our results along the way. Toward that end, we will continue to listen to our E+T students to better understand their experiences and continuously shape our $C U$ Teach Engineering program to meet the needs of engineering students who imagine a future for themselves that includes secondary STEM teaching along the way.

\section{Acknowledgement}

We are extremely grateful to the S.D. Bechtel, Jr. Foundation for its support to our engineering college and education school to create and launch an engineering program expressly designed to simultaneously support STEM teacher licensure. Their "100K in 10" support was invaluable.

\section{References}

1. National Research Council. Engineering in K-12 Education: Understanding the Status and Improving the Prospects. Washington, DC: The National Academies Press, 2009. doi:10.17226/12635

2. McGrath, E., McKay, M., \& Schultz, D. (2008). "Engineering Our Future NJ: Promoting Engineering in K-12 Schools throughout Professional Development, Policy Initiatives, and Partnerships," Proceedings, ASEE Annual Conference \& Expo, Pittsburgh, PA, June. https://peer.asee.org/3431

3. U.S. Census Bureau. (2014). "American Community Survey, Where Do College Graduates Work? A Special Focus on Science, Technology, Engineering and Math.” Retrieved February 4, 2017. https://www.census.gov/dataviz/visualizations/stem/stem-html/

4. Brunhaver, S. R., Matusovich, H. M., Streveler, R. A., Sheppard, S. \& Carrico, C. (2016). "Understanding Engineering Students' Professional Pathways: A Longitudinal Mixed-Methods Study” Proceedings, ASEE Annual Conference \& Expo. New Orleans, LA, June.

5. Forbes, M. H., Bielefeldt, A. R., \& Sullivan, J. F. (2015). “The Choice Opportunity Disparity: Exploring Curricular Choice Opportunities for Engineering vs. Non-Engineering Majors," Proceedings, ASEE Annual Conference \& Exposition, Seattle, WA, June.https://peer.asee.org/24850

6. Zarske, M. S., Cunitz, J. L., Forbes, M. H., \& Sullivan, J. F. (2015). "General Engineering Plus: Creating Community in a Flexible yet Technical Engineering Degree," Proceedings, ASEE Annual Conference \& Exposition, Seattle, WA, June.https://peer.asee.org/24153

7. Hesse-Biber, S. N. Mixed Methods Research: Merging Theory with Practice. New York, NY: Guilford Press, 2010.

8. Maxwell, J. A. Qualitative Research Design: An Interactive Approach (Third Edition, vol. 41, Applied Social Research Methods). Thousand Oaks, CA: SAGE Publications, Inc., 2012. 
9. Miles, M. B., Huberman, A. M., \& Saldaña, J. Qualitative Data Analysis: A Methods Sourcebook. Thousand Oaks, CA: SAGE Publications, Inc., 2013.

10. Zarske, M. S., Vadeen, M. L., Tsai, J. Y., Sullivan, J. F., \& Carlson, D. W. (2016). "Undergraduate Engineers and Teachers: Can Students Be Both?" Proceedings, ASEE Annual Conference \& Expo. New Orleans, LA, June. https://doi.org/10.18260/p.27092

11. Eisenhart, M. "Generalization from Qualitative Inquiry.” In K. Ercikan \& W.-M. Roth (Eds.), Generalizing from Educational Research: Beyond Qualitative and Quantitative Polarization. New York, NY: Routledge, 2009, pp. 51-66.

12. Lichtenstein, G., Loshbaugh, H. G., Claar, B., Chen, H. L., Jackson, K., \& Sheppard, S. D. (2009). “An Engineering Major Does Not (Necessarily) an Engineer Make: Career Decision Making Among Undergraduate Engineering Majors." Journal of Engineering Education, 98(3), 227-234. https://doi.org/10.1002/j.21689830.2009.tb01021.x

13. Samuelson, C., \& Litzler, E. (2013). "Seeing the Big Picture: The Role That Undergraduate Work Experiences Can Play in the Persistence of Female Engineering Undergraduates," Proceedings, ASEE Annual Conference \& Exposition, Atlanta, GA, June. https://peer.asee.org/22443 


\section{Appendix A: Focus Group Protocol, Spring 2015}

Note: These questions are organized by themes, rather than sequentially. The focus group facilitator switched to a particular theme, depending on the conversation trajectory.

\section{Identity}

- What led you to become an engineer?

- What type of person becomes an engineer?

- What are the stereotypes, and what do you believe?

- (For those interested in teaching) What attracted you to teaching?

- What type of person becomes a teacher?

- What are the stereotypes about teachers, and what do you believe?

- Was there anything about teaching that was less attractive to you as an engineer?

- Has there ever been a time when you have had to choose either engineering or teaching? Any times where you could be both? If so, would you describe?

\section{Status \& Stereotypes}

- How does status of the profession of teaching with respect to other professions factor into your decision?

- How do engineering students perceive themselves with respect to students with other majors at $\mathrm{CU}$ ?

- What contributes to these ideas about the two groups?

- Do you know how engineering students are perceived by other students?

- What contributes to these ideas about the two groups?

- How are education students perceived by engineering students?

- What contributes to these ideas about the two groups?

- (If they don't mention these) What roles do the following ideas play:

- knowledge of math/science content

- workload and rigor of coursework

- potential pay scale

- gender

- societal beliefs/family beliefs

- social purpose/value/contribution

- Has your attitude about different stereotypes changed over time?

\section{Reconciling}

- Do you find that you have to "teach" your engineering friends/other friends/family about teaching as a respectable career choice?

- What do you tell them?

- Do any of the reasons you cited earlier (social purpose, "aha" moment, good teachers) support that conversation?

\section{Social Purpose}

- How do you see yourself contributing to society?

- Is engineering a path to contribute to society?

$\circ$ In what way?

$\circ$ How about education? 
- Does one contribute more than the other? Why?

- How much is social purpose playing a role in your decision to pursue a particular profession?

\section{Structural supports and barriers:}

1. Are there any aspects of the $\mathrm{CU}$ Teach $\mathrm{E}+\mathrm{T}$ program sequence that you think might be difficult to complete with respect to your engineering requirements?

2. Do you know how other students have managed this?

3. Would you participate in engineering-specific group meetings to help navigate these challenges?

4. What would you like to see in the courses that would make you feel like a part of the program-like the program is designed for students like you?

\section{Appendix B: Example Interview Protocol-Spring 2016 and Fall 2016}

Note: These interview questions are open-ended general prompts to start conversation and keep it flowing. The questions are asked in any order, depending on the interview trajectory.

1. Tell me about yourself:

- year in school

- major

- favorite classes, this semester or in the past?

2. What do you think about engineering and engineering school so far?

- Has that changed over your semesters here?

3. What do you see yourself doing after graduation?

4. Describe the education classes you've taken/are taking

- How many/ when / what were they?

- How would you compare the education classes to your engineering classes?

- peers

- content

- workflow

- status

- difficulty

- rigor

- future careers?

5. How did you choose to try out CU Teach Engineering?

- or Engineering Plus?

- change majors?

6. Describe how you heard about and chose to enroll in Step 2 this semester. 
- Would you recommend Step 2 to other engineering students?

- Any advice for students enrolling in Step 2 in future semesters?

7. Anything else?

\section{Appendix C: Fall 2015 Teach Engineering Survey}

1. Which emphasis are you most interested in pursuing within your E+ degree?

- Aerospace engineering

A Architectural engineering

a Civil engineering

$\square$ Electrical engineering

¿ Environmental engineering

a Mechanical engineering

u Undecided

2. Which concentration are you most interested in pursuing within your Engineering Plus degree?

C CU Teach Engineering Math (math teacher licensure)

CU Teach Engineering Science (science teacher licensure)

U Undecided

O Other

3. How did you become aware of the CU Teach Engineering Program?

(Please select all that apply.)

Engineering Plus website (College of Engineering)

C CU Teach Engineering website (School of Education)

口 Posted flyer/bulletin board on campus

Advisor from my major department/school

Professor

A Another CU Teach Engineering student

$\square$ Friend

Information table in Engineering Center lobby

Information table in UMC

- Advertisement on Buff Bus

- New-Admitted Student Day Information Fair

- Freshmen orientation during summer

$\square$ Parent

High school counselor/teacher

口 Facebook/Twitter

LA Program

Other (please specify)

4. What are the strengths that you identify in the CU Teach Engineering concentration? (Limit to 150 characters) 
5. Is there a difference between engineering and teaching in general?

$\square$ Yes

$\square$ No

6. Do you think there are any differences between engineering and other CU Teach students on campus?

$\square$ Yes

$\square$ No

7. If yes, please list up to three differences.

8. Do you find it hard to be both an engineering student and a teaching student?

$\square$ Yes

No

9. If yes, please explain:

10. After graduation, do you plan to find work in teaching, engineering, or something that combines both simultaneously?

Teaching

Engineering

A combination of both teaching and engineering

11. Briefly describe your career plan after you graduate college with an engineering degree and a secondary teaching license.

12. Do you think your engineering background influences the way you teach?

ㄱes

No

13. If yes, please explain:

14. What is the impact of engineers that become teachers? (Please give examples, if you have any.) 